\title{
Randomized clinical trial of acetazolamide administration and/or prone positioning in mitigating wound complications following untethering surgeries
}

\author{
Shima Shahjouei, MD, MPH, ${ }^{1}$ Sara Hanaei, MD, MPH, ${ }^{1}$ Zohreh Habibi, MD, ${ }^{1}$ Mostafa Hoseini, PhD, ${ }^{2}$ \\ Saeed Ansari, MD, ${ }^{3}$ and Farideh Nejat, MD, MPH' \\ 'Department of Neurosurgery, Children's Hospital Medical Center, and 2Department of Statistics and Epidemiology, Tehran \\ University of Medical Science, Tehran, Iran; and ${ }^{3}$ Department of Surgery, University of Florida, Gainesville, Florida
}

\begin{abstract}
OBJECTIVE No evidence-based guideline has been approved for the postoperative management of pediatric patients with tethered cord syndrome (TCS). The purpose of this randomized clinical trial was to evaluate the effectiveness of prone positioning and acetazolamide administration on complication rates following spinal cord untethering surgeries.

METHODS From October 2012 to February 2015, patients with a primary diagnosis of TCS who were admitted to the Children's Medical Center Hospital of Iran were randomly allocated to 1 of 4 intervention modality groups postoperatively: 1) Group A, acetazolamide administration for 10 days; 2) Group B, prone positioning for 10 days; 3) Group C, acetazolamide administration and prone positioning for 10 days; and 4) Group D, no intervention. CSF leakage, CSF collection, wound dehiscence, operative site infection, and secondary surgical wound repair were considered failure.

RESULTS A total of 161 patients were enrolled in this study (Group A, $n=39$ [24.2\%]; Group B, $n=41$ [25.5\%]; Group $C, n=39$ [24.2\%]; and Group D, $n=42$ [26.1\%]). The overall failure rate was $12.42 \%$ (20 patients). Complication rates through pooled analyses were as follows: CSF leakage $(n=9,5.6 \%)$, CSF collection $(n=12,7.5 \%)$, wound dehiscence $(n=2,1.2 \%)$, and infection of operation site $(n=3,1.9 \%)$. Two patients $(1.2 \%)$ required surgical secondary wound repair due to complications. CSF leakage and collection rates were significantly lower in patients who underwent prone positioning ( $p=0.042$ and 0.036 , respectively). The administration of acetazolamide, either isolated or in combination with prone positioning, not only could not significantly lower the complication rates, but also added the burden of side effects. CONCLUSIONS The current study demonstrates the possible role of prone positioning in mitigating the complication rates subsequent to untethering surgeries.

Clinical trial registration no.: NCT01867268 (clinicaltrials.gov)

http://thejns.org/doi/abs/10.3171/2015.8.PEDS15393
\end{abstract}

KEY WORDS prone positioning; acetazolamide; cerebrospinal fluid leakage; cerebrospinal fluid collection; wound dehiscence; spine

$\mathrm{T}$ ETHERED cord syndrome (TCS) is a clinical condition resulting from traction on the conus medullaris. ${ }^{2,14,38}$ Low positioning of conus medullaris, fatty filum (FF), lipomyelomeningocele (LMMC), myelomeningocele, split cord malformation (SCM), and dermal sinus (DS) are some conditions that can cause TCS. $2,7,14,29,34,38$ While asymptomatic in some patients, TCS can present with pain, neurological deterioration, and orthopedic or urological aggravation., 2,14,38 An untethering procedure may be associated with serious complications such as CSF leakage, CSF collection, wound dehiscence, and infection. ${ }^{19,27,30,31}$ Despite a vast investigation of preventive interventions for such complications, ${ }^{4,8,18,21,27}$ no evidenced-based guideline has yet been published.

Although prophylactic administration of acetazolamide and/or bed rest following the intradural operation are acceptably used by both neurosurgeons and orthopedic surgeons, no high-level approved evidence exists regarding whether and how to use these measures.

To the best of our knowledge, no randomized trial has assessed the prophylactic effect of acetazolamide in reducing complications following spinal surgeries. Likewise,

ABBREVIATIONS DS = dermal sinus; FF = fatty filum; LMMC = lipomyelomeningocele; $S C M=$ slit cord malformation; TCS = tethered cord syndrome . ACCOMPANYING EDITORIAL See pp 657-658. DOI: 10.3171/2015.9.PEDS15484.

SUBMITTED June 28, 2015. ACCEPTED August 10, 2015.

INCLUDE WHEN CITING Published online January 29, 2016; DOI: 10.3171/2015.8.PEDS15393. 
only a limited number of trials have been published on the duration of postoperative bed rest. ${ }^{8,30,31}$ In this study, we conducted a randomized, 4-arm, controlled clinical trial to assess the effect of acetazolamide administration and/ or prone positioning on the outcome of pediatric patients who underwent untethering surgeries and discuss other factors that may influence the rate of failure.

\section{Methods}

This study was conducted from October 2012 to February 2015 at the Children's Medical Center Hospital in Tehran, Iran. The study was approved by the Medical Ethics and History of Medicine Research Center of Tehran University of Medical Sciences and registered in the Iranian Registry of Clinical Trials (no. IRCT2012100611023N). This study was also registered with the ClinicalTrials.gov database (http://clinicaltrials.gov), and its registration no. is NCT01867268. All patients were enrolled in this study voluntarily and informed consent was obtained from the parents or legal advocates of the patients.

\section{Eligibility Criteria}

All the patients who needed spinal cord untethering surgery were screened, and those with an initial diagnosis of primary tethered cord with fatty or thick filum terminale, LMMC, SCM, DS, or any other closed spinal dysraphism requiring intradural intervention were included. Patients with an infected dermoid tumor, intramedullary abscess, myelomeningocele, meningocele, or those who had hydrocephalus were excluded. All patients with a tethered cord and thick filum had a conus medullaris at a level much lower than a normally accepted level (distal to the L-3 level). The presence of neurological symptoms was not mandatory to be included in the study, but all clinically asymptomatic patients had at least 1 pathological finding in their urological studies, including radiological or urodynamic assessment. Other exclusion criteria were patients seeking an untethering reoperation or those older than 18 years of age on admission.

\section{Study Design and Sample Size}

Because the main purpose of this study was to evaluate the effect of applying two main factors (prone positioning and acetazolamide administration) on outcome, a factorial study was the most appropriate study design, in which participants were allocated to receive neither postoperative measure, one or the other, or both together. A factorial trial enabled us to evaluate both the separate effects of each intervention and the benefits of receiving a combination of both interventions. ${ }^{29}$ It is worth noting that the 2 postoperative interventions in our study are independent measures, which is the main assumption of the factorial design. Based on the factorial trial design ${ }^{29}$ and considering $80 \%$ power and an $\alpha$ of 0.05 , a minimum of 144 patients was calculated.

\section{Randomization and Allocation of the Patients to Interventions}

Randomization was performed through a computer- based 4-factor randomization block design. All the included cases (161 patients) were randomly assigned to 1 of the 4 intervention modality groups by taking 1 of the opaque enveloped cards postoperatively: Group A, acetazolamide administration for 10 days; Group B, prone positioning for 10 days; Group C, acetazolamide administration and prone positioning for 10 days; and Group D, no intervention.

Both the medical staff and the parents of the patient were kept blinded to the intervention before and through the operation. Thus, the intervention allocated to the patient was not affected by the indication (LMMC, DS, $\mathrm{SCM}$, or FF) or technique of the surgery (e.g., whether or not a fascial patch graft was used). Keeping parents blinded could prevent selection bias, influenced by the parents' desire for allocating their children to a given group. The analyzer was also kept blind from the entity of the interventions and indications.

\section{Surgical Considerations}

All surgeries were performed in an elective setting. All patients underwent surgical interventions based on individual indications according to preoperative diagnoses and images. The dura and fascia were closed in a watertight fashion after completing the intradural procedure. In the case of a dural or fascial defect, a fascial patch graft was used to fill the gap. No sealant or adhesive material was used to fortify sutures. Skin closure was performed in a multiple-layer fashion with absorbable sutures. At the end of the procedure, a compressive dressing bandage was applied.

\section{Interventions and Postoperative Care}

All patients underwent a routine and similar protocol of wound care following the surgery. Operative sites were cleaned with Povidone-iodine and a compressive dressing was applied daily up to the discharge day. Acetazolamide was administered as tablet or dissolved in water, and dosing was based on the patients' weight $(20 \mathrm{mg} / \mathrm{kg} /$ day). Due to ethical considerations and poor compliance of the younger patients, we did not use physical restraints for maintaining position; instead, we kept the patients prone with the aid of parents and trained nurses. Toddlers received incentives and older patients were convinced to lay prone. The patients maintained the position to the end of the tenth day, even after being discharged from the hospital.

During hospitalization, the compliance of keeping the prone position was controlled by the staff nurse. Compliance for maintaining the prone position for the entire 10 days was checked on the first visit after discharge by asking the parents. The patients in the no-intervention group were free to maintain any position and/or be out of bed from the day after surgery.

\section{Outcome Assessment}

Cerebrospinal fluid leakage, CSF collection, wound dehiscence, operative site infection, and secondary wound repair through the first month following the surgery were considered failure. CSF leakage was defined as fluid rush- 
ing out from the wound, confirmed by 2 attending neurosurgeons (F.N. and Z.H.) in separate settings. CSF collection was considered as visible subcutaneous fluid collection or subcutaneous fluctuation confirmed by 2 attending neurosurgeons in separate settings, without any superficial ultrasound probe assessment or MRI. In all patients with CSF subcutaneous fluid collection or subcutaneous fluctuation, subcutaneous fluid tapping was conducted to rule out hematoma formation. Wound dehiscence was defined by wound ruptures along surgical sutures, either because the surface layers separated or the whole wound split open. Wound infection was confirmed with culture and staining of the samples from the operative site. Postoperative evaluations (performed daily during hospitalization and about 4 weeks after discharge) were conducted by 2 attending neurosurgeons.

\section{Complication Management}

In the case of CSF leakage, CSF collection, and wound dehiscence, in addition to relevant measures such as surgical debridement or simple wound repair, and regardless of the primary intervention group, the patient received acetazolamide and was kept prone until complete wound healing. In the case of wound infection, an antibiotic was administered according to the culture and antibiogram.

\section{Statistical Analysis}

Statistical analyses were performed using SPSS (version 22, IBM) and Stata (version 12.0, StataCorp). Data are presented as either means \pm SDs (range), or proportions. The normality of the parameters was checked using the Kolmogorov-Smirnov test. For comparison of quantitative variables (such as weight, age, and the duration of the surgery) in the 4 intervention groups of the study, 1-way ANOVA was used. The chi-square test was used for comparing the proportions of patients who underwent grafting, in addition to the number of males and females in each group. For the comparison of surgical indications between intervention groups (major indication, as well as second and third associated defect), Fisher's exact test was used, as the frequency of complications in the groups was small.

Sex, age, and weight of the patients on the day of the operation, use of a fascia graft, duration of surgery, and the main indication of the surgery (independent variables) were used to predict complications (dependent variable) in a binary logistic regression analysis. All $\mathrm{p}$ values less than 0.05 were considered significant in all analyses.

\section{Results}

A total of 161 patients were enrolled in this study. Patients were randomly assigned to 1 of the 4 intervention groups after surgery (Group A [ $\mathrm{n}=39,24.2 \%]$; Group B [n $=41,25.5 \%]$; Group C [ $\mathrm{n}=39,24.2 \%]$; Group D [ $=$ 42, 26.1\%]). Among those who were excluded, 87 patients had myelomeningocele, 31 patients were admitted due to repeat surgery for myelomeningocele or LMMC, and 7 patients were treated for complicated DSs with abscess.

Seventy-one patients $(44.1 \%)$ were male. The mean age of the patient population was $3.14 \pm 3.80$ years old (range
1-5527 days), and the average weight of the patients on the day of the operation was $12.10 \pm 11.11 \mathrm{~kg}$ (range 1.4-73 $\mathrm{kg}$; Table 1).

Pooled analysis of all patients in the 4 groups revealed that 78 patients $(48.4 \%)$ underwent surgery for LMMC. Other indications for surgery were primary TCS (28\%), SCM (12.4\%), and uncomplicated DS (11.2\%). A total of 30 patients (18.6\%) had a second associated anomaly, and 2 patients $(1.2 \%)$ had a third associated abnormality (Table 2 ). Duraplasty was conducted in 55 patients (34.2\%). The mean operative time was $171.79 \pm 78.30$ minutes (range 40-510 minutes). Data for each intervention group is provided in Table 1.

The distribution of patient sex, age, and weight on the day of the operation, medical indications for surgery (LMMC, SCM, FF, and DS), and the rate of duraplasty were similar among categories of intervention. The mean duration of procedures was not remarkably different among patients who underwent these 4 indications (LMMC, SCM, FF, or DS). However, the duration of the operation varied significantly between the 4 intervention groups (A-D), with the lowest mean in Group B (130 minutes) and highest in Group D (216 minutes; p < 0.01). Subsequently, all analyses were performed with adjustment for this factor and by splitting the duration of the operation into 2 subgroups ( $<$ 120 minutes and > 120 minutes).

Considering all 4 intervention groups together, the complications and their frequencies were as follows: CSF leak $(\mathrm{n}=9,5.6 \%)$, CSF collection $(\mathrm{n}=12,7.5 \%)$, wound dehiscence $(\mathrm{n}=2,1.2 \%)$, and infection of operative site $(\mathrm{n}=3,1.9 \%$; Table 3$)$. Two patients $(1.2 \%)$ required surgical secondary wound repair due to wound dehiscence. Hematoma was detected in 1 patient $(0.62 \%)$, which was not considered wound failure. Some patients experienced more than 1 complication, thus the overall failure rate was $12.42 \%$ (20 patients). Details on complication rates in each intervention group are presented in Table 3.

The analyses of complications through each intervention group (A-D) yielded a borderline difference in CSF leak and significant difference in CSF collection rates among categories of intervention $(\mathrm{p}=0.06$ and 0.02 , respectively; Table 3).

In the factorial design and considering the patients in Groups B and C together, patients who underwent prone positioning had significantly lower rates of CSF leak and collection ( $p=0.042$ and 0.036 , respectively). Nonetheless, the association between prone positioning and wound dehiscence or operative site infection was not significant (Table 4).

Rates of complications in patients taking acetazolamide were not significantly different from others. Among all those who received acetazolamide, $2(2.56 \%)$ patients experienced diarrhea without bacteria growth in stool examination, 3 (3.84\%) had acidosis, 2 (2.56\%) experienced electrolyte imbalance, and $4(5.12 \%)$ had loss of appetite. One patient needed admission to the intensive care unit due to severe acidosis and electrolyte imbalance. Applying both modalities (prone positioning and acetazolamide administration) simultaneously did not mitigate the rate of complications.

Binary logistic regression did not find any meaningful 
TABLE 1. Patient characteristics in each intervention group

\begin{tabular}{|c|c|c|c|c|c|c|}
\hline \multirow[b]{2}{*}{ Characteristics } & \multicolumn{4}{|c|}{ Intervention } & \multirow[b]{2}{*}{ Total } & \multirow[b]{2}{*}{$\mathrm{p}$ Value } \\
\hline & Acetazolamide & $\begin{array}{c}\text { Prone } \\
\text { Positioning }\end{array}$ & $\begin{array}{l}\text { Acetazolamide \& } \\
\text { Prone Positioning }\end{array}$ & No Intervention & & \\
\hline No. of patients & 39 & 41 & 39 & 42 & 161 & \\
\hline $\operatorname{Sex}(\%)$ & & & & & & 0.11 \\
\hline Female & $18(46.2)$ & $19(46.3)$ & $26(66.7)$ & $27(64.3)$ & $90(55.9)$ & \\
\hline Male & $21(53.8)$ & $22(53.7)$ & $13(33.3)$ & $15(35.7)$ & $71(44.1)$ & \\
\hline Age (days) & & & & & & 0.40 \\
\hline Mean \pm SD & $828.3 \pm 942.0$ & $1138.1 \pm 1500$ & $1177 \pm 1530.6$ & $1389 \pm 1442.9$ & $1146.5 \pm 1385.6$ & \\
\hline Range & $1-3285$ & $65-4745$ & $1-5527$ & $1-438$ & $1-5527$ & \\
\hline Weight (kg) & & & & & & 0.40 \\
\hline Mean \pm SD & $11.08 \pm 12.20$ & $10.96 \pm 8.60$ & $11.33 \pm 8.37$ & $14.66 \pm 14$ & $12.10 \pm 11.11$ & \\
\hline Range & $2-73$ & $4.2-37$ & $3.8-37$ & $1.4-68$ & $1.4-73$ & \\
\hline No. w/ dura graft (\%) & $14(35.9)$ & $14(34.1)$ & $11(28.2)$ & $16(38.1)$ & $55(34.2)$ & 0.81 \\
\hline Duration of operation (min) & & & & & & 0.00 \\
\hline Mean \pm SD & $160.8 \pm 66.2$ & $129.7 \pm 67.0$ & $181.3 \pm 58.8$ & $215.9 \pm 90.2$ & $171.79 \pm 78.30$ & \\
\hline Range & $40-300$ & $40-270$ & $60-345$ & $60-510$ & $40-510$ & \\
\hline
\end{tabular}

association between each of the complications (CSF leak, CSF collection, wound dehiscence, and infection) and basal parameters (sex, age, and weight of the patients on operation day), use of fascia graft, and duration of or indication for surgery. Complication rates did not vary among patients with different indications for surgery (LMMC, SCM, FF, DS). We also could not find any increment in complication rates when comparing the patients who underwent LMMC and the other 3 indications for surgery (Table 5).

\section{Discussion}

Several conditions including LMMC, SCM, FF, and DS are associated with TCS. Untethering of a tethered spi-

TABLE 2. Surgical indications in each intervention group

\begin{tabular}{|c|c|c|c|c|c|c|}
\hline \multirow[b]{2}{*}{ Characteristics } & \multicolumn{4}{|c|}{ Intervention } & \multirow[b]{2}{*}{ Total } & \multirow{2}{*}{$\begin{array}{c}p \\
\text { Value* }\end{array}$} \\
\hline & Acetazolamide & Prone Positioning & Acetazolamide \& Prone Positioning & No Intervention & & \\
\hline Major indication for surgery (\%) & & & & & & 0.32 \\
\hline LMMC & $18(46.2)$ & $22(53.7)$ & $24(61.5)$ & $14(33.3)$ & $78(48.4)$ & \\
\hline DS & $4(10.3)$ & $5(12.2)$ & $1(2.6)$ & $8(19.0)$ & $18(11.2)$ & \\
\hline Primary TCS & $12(30.8)$ & $10(24.4)$ & $10(25.6)$ & $13(31.0)$ & $45(28.0)$ & \\
\hline SCM syndrome & $5(12.8)$ & $4(9.8)$ & $4(10.3)$ & $7(16.7)$ & $20(12.4)$ & \\
\hline Second associated defect (\%) & & & & & & 0.33 \\
\hline DS & 0 & $1(2.4)$ & 0 & $1(2.4)$ & $2(1.2)$ & \\
\hline Tumor & $4(10.3)$ & 0 & 0 & $1(2.4)$ & $5(3.1)$ & \\
\hline Lipoma & $1(2.6)$ & 0 & 0 & $2(4.8)$ & $3(1.9)$ & \\
\hline Syrinx & $2(5.1)$ & 0 & $1(2.6)$ & $1(2.4)$ & $4(2.5)$ & \\
\hline Arachnoid cyst & $3(7.7)$ & 0 & 0 & $3(7.1)$ & $6(3.7)$ & \\
\hline SCM & 0 & 0 & $1(2.6)$ & $2(4.8)$ & $3(1.9)$ & \\
\hline Scoliosis & $2(5.1)$ & 0 & 0 & 0 & $2(1.2)$ & \\
\hline Twin in twin & $1(2.6)$ & 0 & 0 & $1(2.4)$ & $1(0.6)$ & \\
\hline Sacral agenesis & 0 & $1(2.4)$ & $1(2.6)$ & 0 & $2(1.2)$ & \\
\hline Human tail & 0 & 0 & 0 & $1(2.4)$ & $1(0.6)$ & \\
\hline Intramedullary abscess & 0 & $1(2.4)$ & 0 & 0 & $1(0.6)$ & \\
\hline Third associated defect (\%) & & & & & & 0.50 \\
\hline Syrinx & 0 & 0 & $1(2.6)$ & 0 & $1(0.6)$ & \\
\hline Scoliosis & 0 & 0 & 0 & $1(2.4)$ & $1(0.6)$ & \\
\hline
\end{tabular}

\footnotetext{
* Fisher's exact test.
} 
TABLE 3. Complications following untethering surgeries, considering each intervention group separately*

\begin{tabular}{|c|c|c|c|c|c|c|}
\hline \multirow[b]{2}{*}{ Complications } & \multicolumn{4}{|c|}{ Interventions (\%) } & \multirow[b]{2}{*}{ Total } & \multirow[b]{2}{*}{$\mathrm{p}$ Value } \\
\hline & Acetazolamide & Prone Positioning & Acetazolamide \& Prone Positioning & No Intervention & & \\
\hline CSF leak & $3(7.7)$ & 0 & $1(2.6)$ & $5(11.9)$ & $9(5.6)$ & 0.06 \\
\hline CSF collection & $5(12.8)$ & $2(4.9)$ & 0 & $5(11.9)$ & $12(7.5)$ & 0.02 \\
\hline Wound dehiscence & 0 & 0 & $2(5.1)$ & 0 & $2(1.2)$ & 0.11 \\
\hline Operative site infection & 0 & $2(4.9)$ & $1(2.6)$ & 0 & $3(1.9)$ & 0.42 \\
\hline Surgical wound repair & $1(2.6)$ & $1(2.4)$ & 0 & 0 & $2(1.2)$ & 0.61 \\
\hline
\end{tabular}

${ }^{*} p$ values were calculated considering each postoperative intervention group separately and without applying factorial analyses.

nal cord is recommended in symptomatic or even asymptomatic patients, although there are some debates on the latter condition. ${ }^{25,30,32}$ The end point of closure in all untethering surgeries (with no respect to the underlying pathology) is the same and contains the watertight closure of dura and fascia. Despite the safety of the technique, complications such as CSF leakage, CSF collection, wound dehiscence, and infection are still reported, ${ }^{19,23,27,30,31}$ and albeit rare, they might be serious, leading to meningitis or encephalitis. ${ }^{21,31,34,40}$

Although various interventions are introduced as protective modalities for reducing the risk of these complications, ${ }^{4,18}$ no evidenced-based or accepted guideline has yet been suggested. Therefore, we designed this study to evaluate the effectiveness of these two routinely practiced postsurgical measures (acetazolamide administration and prone positioning) in patients who underwent untethering of the spinal cord.

\section{Bed Rest}

Bed rest is a broadly accepted postoperative care following numerous surgeries. ${ }^{2,47,8,28}$ However, there is no consistency between surgeons on indication, duration, and position of the bed rest for prevention and management of CSF complications following lumbosacral spinal surgeries. ${ }^{9,12,16,26,29,31}$

Experimental models of the dural reparative process showed that primary fibroblastic bridging of the durotomy appears at postoperative Day 6, and closure of the defect occurs at Day $10 .{ }^{3}$ Some spine surgeons determine the length of bed rest on this basis. ${ }^{4}$ In the All India Institute of Medical Sciences ${ }^{27}$ almost all patients with spinal dysraphism are nursed in the prone position, as a routine protocol, for a duration of approximately 7-10 days. However, surveys on current practice in postoperative accidental durotomy showed a trend toward minimizing the duration of bed rest; the majority of surgeons recommend bed rest up to 72 hours and almost $25 \%$ of them allow immediate mobilization of the patients. 9,11

Some authors have stated that solitary bed rest is ineffective in preventing the consequences following incidental durotomy, ${ }^{10,12}$ and the rate of revision surgeries is the same in patients who underwent bed rest and in those with early mobilization..$^{9,16}$ Despite this opinion, isolated flat positioning is suggested as an effective CSF leak management strategy following tethered cord release..$^{2,29}$

Some recent studies were published on this issue to put an end to this discrepancy. Chern and colleagues ${ }^{8}$ studied 3 different postoperative care strategies: supine positioning for 48 hours (1 day in the hospital and then keeping the position for another day at home), or 72 hours either as 3 days in the hospital or discharge after the first day. By their conclusion, bed rest can be minimized to 48 hours without an additive complication rate.

In the study by Ogiwara et al., ${ }^{31}$ patients were kept supine for 8 days following surgery. In comparison with 2 previously published studies with 24-72 hours of supine positioning, ${ }^{8,39}$ those who kept the position for 8 days had lower pseudomeningocele formation and CSF leakage rates. Further comparison of the patients who were kept supine for either 72 hours or 8 days but with a unique surgical technique and dural closure did not find any significant difference between these 2 cohorts. ${ }^{30}$ Ogiwara and colleagues also mentioned that the preliminary analysis of 1-day bed rest in their ongoing study was satisfactory, and they suggested future studies on the elimination of bed rest from postoperative care protocols..$^{20}$

In our study, the analysis of complications in each intervention group (comparison between factorial cells) yielded a borderline association between position and CSF

TABLE 4. Complications following untethering surgeries based on factorial design

\begin{tabular}{lcccc}
\hline \multirow{2}{*}{ Complications } & \multicolumn{4}{c}{ Intervention Modalities $(\%)$} \\
\cline { 2 - 4 } & Acetazolamide Administration $(\mathrm{n}=78)$ & Prone Positioning $(\mathrm{n}=80)$ & No Intervention $(\mathrm{n}=42)_{\mathrm{p} \text { Values }}{ }^{*}$ \\
\hline CSF leak & $4(5.13)$ & $1(1.25)$ & $5(11.9)$ & 0.042 \\
\hline CSF collection & $5(6.41)$ & $2(2.50)$ & $5(11.9)$ & 0.036 \\
\hline Wound dehiscence & $2(2.57)$ & $2(2.50)$ & 0 & 0.091 \\
\hline Operative site infection & $1(1.28)$ & $3(3.75)$ & 0 & 0.320 \\
\hline Surgical wound repair & $1(1.28)$ & $1(1.25)$ & 0.054 \\
\hline
\end{tabular}

* Exact logistic regression. 
TABLE 5. Comparison of complication rates between patients with different indications of surgery

\begin{tabular}{|c|c|c|}
\hline \multirow[b]{2}{*}{ Complications } & \multicolumn{2}{|c|}{$p$ Values } \\
\hline & $\begin{array}{l}\text { Between Patients w/ } \\
\text { Different Indications } \\
\quad \text { for Surgery* }\end{array}$ & $\begin{array}{l}\text { Between Those } \\
\text { Who Underwent } \\
\text { LMMC \& Other } 3 \\
\text { Indications }\end{array}$ \\
\hline CSF leak† & 0.15 & $>0.9$ \\
\hline CSF collection $\ddagger$ & 0.14 & 0.07 \\
\hline Wound dehiscence $\dagger$ & 0.10 & 0.23 \\
\hline Operative site infection† & 0.15 & 0.11 \\
\hline
\end{tabular}

leakage $(p=0.06)$ and a meaningful association between prone positioning and CSF collection $(\mathrm{p}=0.02)$. By the aid of the factorial design and corresponding analyses, we cumulatively considered all patients who underwent prone positioning (78 children [48.4\%]) and reduced the effect of acetazolamide administration on those from Group C of the intervention modality. This analysis suggested that prone positioning can significantly eliminate the rate of CSF leakage and collection ( $\mathrm{p}=0.042$ and 0.036 , respectively).

Based on our knowledge, this is the first randomized clinical trial that shows the effectiveness of prone positioning in preventing postoperative complications. The dissimilarity of our findings with previous reports can be assigned to the position (prone instead of supine) and longer duration of the bed rest in our study.

Changing the body position from horizontal to standing posture increases the mean lumbar subarachnoid and CSF pressure. ${ }^{5}$ Similarly, dural sac cross-sectional area at the level of intervertebral disc, as a direct function of CSF pressure, is lower in the supine position in comparison with standing posture. ${ }^{15}$ The pressure of CSF in the prone position is even lower than in the supine position..$^{24,33}$ Postural variation of CSF pressure affects intracanal pressure (inside the spinal canal) in almost the same patterns ${ }^{13,35}$ and both CSF and intracanal pressure are lowest in the prone position. ${ }^{13}$ Although prone positioning was significantly associated with a lower rate of complications in comparison with the free position, its superiority to the supine position should be evaluated in further studies. Moreover, the 10-day period of keeping pediatric patients prone is unacceptable to most of the parents. Therefore, we are designing another study in which the length of prone positioning is mitigated.

Anatomical factors such as fat tissue thickness at the operation site might be the probable causes for absence of correlation between wound dehiscence and positioning. ${ }^{4,9}$

\section{Acetazolamide Administration}

Acetazolamide reduces CSF production and flow by inhibiting the choroid plexus carbonic anhydrase enzyme, resulting in CSF volume and intracranial pressure reduction. $., 6,17,37$ Acetazolamide had been widely used for the management of CSF leakage. ${ }^{6,22,23,41}$ It has also been suggested that early acetazolamide administration can prevent CSF leakage in high-risk patients. ${ }^{1}$ In the case of intradural spine surgeries, acetazolamide is administered routinely as a prophylactic agent in some centers, ${ }^{21,27}$ but its effectiveness has not yet been studied.

In this study, we assessed the complication rates between patients who received acetazolamide and those who did not. Either through a comparison among 4 groups of intervention or as a cumulative analysis of those who received acetazolamide $(\mathrm{n}=78,48.4 \%)$, we could not detect any significant reduction in complication rates. Instead, it appears that we added the risk of medication side-effects to these patients.

Acetazolamide prevents hydration of carbon dioxide and dehydration of carbonic acid, causing metabolic acidosis. Acetazolamide also results in renal loss of $\mathrm{HCO}_{3}$ ions (that carry sodium, water, and potassium) and makes the patient susceptible to electrolyte imbalances such as hyponatremia, hypokalemia, and metabolic acidosis. ${ }^{36}$ In the current study, among those who received acetazolamide, 2 patients $(2.56 \%)$ got diarrhea without any evidence of infection, 3 (3.84\%) experienced acidosis, and 2 (2.56\%) had hypokalemia. One patient required admission to the ICU due to the severity of the acidosis and electrolyte imbalance. Four patients $(5.12 \%)$ lost their appetite during the course of treatment, which was ameliorated with cessation of acetazolamide. None of the patients in the control group presented with any of the aforementioned complications.

\section{Other Factors Predicting the Outcome}

We could not find any correlation between target outcomes and basal parameters such as sex, age, and weight of the patients on the operation day. Similarly, complication rates were the same in the subgroups of indications for surgery (LMMC, DS, SCM, and FF). Interestingly, in contradiction to the former impression that LMMC surgeries are associated with a high rate of CSF leak and wound complications, ${ }^{42}$ our study showed that LMMC does not increase the aforementioned unwanted events in comparison with the other 3 operative modalities (Table 5). We also could not find any association between the application of duraplasty or duration of the surgery and outcomes.

Discounting the effect of basal parameters as well as postoperative care strategies on the outcome of spinal surgeries will bring more attention to the nature of the defect and operative techniques. One possible predictor of the outcome would be the way fascia and muscles are closed ${ }^{30,43}$ In this study, we used watertight closure of the dura and multilayer closure of the fascia and muscles to minimize failure.

\section{Limitations of the Study}

The most critical limitation of this study is the small sample size. To overcome this limitation, we used the factorial design for determining the sample size and analyzing the intervention groups. We also considered the occurrence of CSF leak and collection based on the opinion of 2 attending neurosurgeons and did not include any biochemical or imaging modalities. Likewise, the volume and duration of CSF complications and the size of prima- 
ry lesions and dural incisions were not considered in the analyses.

\section{Conclusions}

This study suggests that positioning the patients prone for a duration of 10 days might decrease the rate of CSF complications after an untethering procedure. However, the utility of this measure, and also the possibility of a shorter period of prone positioning, should be assessed. We also recommend that prophylactic acetazolamide administration is not necessary for postoperative spinal surgeries and the rate of side effects might surpass its potential benefit. Further studies on the duration and type of position by considering the size of the dural incision are needed to make a final conclusion.

\section{References}

1. Abrishamkar S, Khalighinejad N, Moein P: Analysing the effect of early acetazolamide administration on patients with a high risk of permanent cerebrospinal fluid leakage. Acta Med Iran 51:467-471, 2013

2. Bowman RM, Mohan A, Ito J, Seibly JM, McLone DG: Tethered cord release: a long-term study in 114 patients. J Neurosurg Pediatr 3:181-187, 2009

3. Cain JE Jr, Lauerman WC, Rosenthal HG, Broom MJ, Jacobs RR: The histomorphologic sequence of dural repair. Observations in the canine model. Spine (Phila Pa 1976) 16 (8 Suppl):S319-S323, 1991

4. Cammisa FP Jr, Girardi FP, Sangani PK, Parvataneni HK, Cadag S, Sandhu HS: Incidental durotomy in spine surgery. Spine (Phila Pa 1976) 25:2663-2667, 2000

5. Carlson GD, Oliff HS, Gorden C, Smith J, Anderson PA: Cerebral spinal fluid pressure: effects of body position and lumbar subarachnoid drainage in a canine model. Spine (Phila Pa 1976) 28:119-122, 2003

6. Chaaban MR, Illing E, Riley KO, Woodworth BA: Acetazolamide for high intracranial pressure cerebrospinal fluid leaks. Int Forum Allergy Rhinol 3:718-721, 2013

7. Chern JJ, Dauser RC, Whitehead WE, Curry DJ, Luerssen TG, Jea A: The effect of tethered cord release on coronal spinal balance in tight filum terminale. Spine (Phila Pa 1976) 36:E944-E949, 2011

8. Chern JJ, Tubbs RS, Patel AJ, Gordon AS, Bandt SK, Smyth $\mathrm{MD}$, et al: Preventing cerebrospinal fluid leak following transection of a tight filum terminale. J Neurosurg Pediatr 8:35-38, 2011

9. Clajus C, Stockhammer F, Rohde V: The intra- and postoperative management of accidental durotomy in lumbar spine surgery: results of a German survey. Acta Neurochir (Wien) 157:525-530, 2015

10. Eismont FJ, Wiesel SW, Rothman RH: Treatment of dural tears associated with spinal surgery. J Bone Joint Surg Am 63:1132-1136, 1981

11. Gautschi OP, Stienen MN, Smoll NR, Corniola MV, Tessitore $\mathrm{E}$, Schaller K: Incidental durotomy in lumbar spine surgerya three-nation survey to evaluate its management. Acta Neurochir (Wien) 156:1813-1820, 2014

12. Guerin P, El Fegoun AB, Obeid I, Gille O, Lelong L, Luc S, et al: Incidental durotomy during spine surgery: incidence, management and complications. A retrospective review. Injury 43:397-401, 2012

13. Hanai K, Kawai K, Itoh Y, Satake T, Fujiyoshi F, Abematsu $\mathrm{N}$ : Simultaneous measurement of intraosseous and cerebrospinal fluid pressures in lumbar region. Spine (Phila Pa 1976) 10:64-68, 1985

14. Hertzler DA II, DePowell JJ, Stevenson CB, Mangano FT:
Tethered cord syndrome: a review of the literature from embryology to adult presentation. Neurosurg Focus 29(1):E1, 2010

15. Hirasawa Y, Bashir WA, Smith FW, Magnusson ML, Pope $\mathrm{MH}$, Takahashi K: Postural changes of the dural sac in the lumbar spines of asymptomatic individuals using positional stand-up magnetic resonance imaging. Spine (Phila Pa 1976) 32:E136-E140, 2007

16. Hodges SD, Humphreys SC, Eck JC, Covington LA: Management of incidental durotomy without mandatory bed rest. A retrospective review of 20 cases. Spine (Phila Pa 1976) 24:2062-2064, 1999

17. Jafarzadeh F, Field ML, Harrington DK, Kuduvalli M, Oo A, Kendall J, et al: Novel application of acetazolamide to reduce cerebrospinal fluid production in patients undergoing thoracoabdominal aortic surgery. Interact Cardiovasc Thorac Surg 18:21-26, 2014

18. Jankowitz BT, Atteberry DS, Gerszten PC, Karausky P, Cheng BC, Faught R, et al: Effect of fibrin glue on the prevention of persistent cerebral spinal fluid leakage after incidental durotomy during lumbar spinal surgery. Eur Spine J 18:1169-1174, 2009

19. Jindal A, Mahapatra AK, Kamal R: Spinal dysraphism. Indian J Pediatr 66:697-705, 1999

20. Kestle JRW: Editorial. Bed rest after filum surgery. J Neurosurg Pediatr 15:459-460, 2015

21. Kumar R: Split cord malformation (occult spina bifida): An Indian scenario. JK Sci 7:192-194, 2005

22. Kumar R, Singh SN: Spinal dysraphism: trends in northern India. Pediatr Neurosurg 38:133-145, 2003

23. Kumar R, Singh SN, Bansal KK, Singh V: Comparative study of complex spina bifida and split cord malformation. Indian J Pediatr 72:109-115, 2005

24. Lee ST: Intracranial pressure changes during positioning of patients with severe head injury. Heart Lung 18:411-414, 1989

25. Levi B, Sugg KB, Lien SC, Kasten SJ, Muraszko KM, Maher $\mathrm{CO}$, et al: Outcomes of tethered cord repair with a layered soft tissue closure. Ann Plast Surg 70:74-78, 2013

26. Low JCM, von Niederhäusern B, Rutherford SA, King AT: Pilot study of perioperative accidental durotomy: does the period of postoperative bed rest reduce the incidence of complication? Br J Neurosurg 27:800-802, 2013

27. Mahapatra AK: Spinal dysraphism controversies: AIIMS experiences and contribution. Indian J Neurosurg 1:4-8, 2012

28. Marco RAW, Stuckey RM, Holloway SP: Prolonged bed rest as adjuvant therapy after complex reconstructive spine surgery. Clin Orthop Relat Res 470:1658-1667, 2012

29. Muthukumar N: Congenital spinal lipomatous malformations: part II-Clinical presentation, operative findings, and outcome. Acta Neurochir (Wien) 151:189-197, 2009

30. Ogiwara H, Joko M, Takado M, Uematsu K, Kameda M, Sasaki N, et al: Duration of the horizontal decubitus position for prevention of cerebrospinal fluid leakage following transection of a tight filum terminale. J Neurosurg Pediatr 15:461-464, 2015

31. Ogiwara H, Morota N, Joko M: Duration of horizontal decubitus after section of a tight filum terminale as a means to prevent cerebrospinal fluid leakage. Surg Neurol Int 3:113117,2012

32. Ostling LR, Bierbrauer KS, Kuntz C IV: Outcome, reoperation, and complications in 99 consecutive children operated for tight or fatty filum. World Neurosurg 77:187-191, 2012

33. Reinprecht A, Greher M, Wolfsberger S, Dietrich W, Illievich UM, Gruber A: Prone position in subarachnoid hemorrhage patients with acute respiratory distress syndrome: effects on cerebral tissue oxygenation and intracranial pressure. Crit Care Med 31:1831-1838, 2003 
34. Rufener SL, Ibrahim M, Raybaud CA, Parmar HA: Congenital spine and spinal cord malformations-pictorial review.

AJR Am J Roentgenol 194 (3 Suppl):S26-S37, 2010

35. Shah JL: Effect of posture on extradural pressure. Br J Anaesth 56:1373-1377, 1984

36. Subudhi AW, Dimmen AC, Julian CG, Wilson MJ, Panerai RB, Roach RC: Effects of acetazolamide and dexamethasone on cerebral hemodynamics in hypoxia. J Appl Physiol (1985) 110:1219-1225, 2011

37. Wall M, McDermott MP, Kieburtz KD, Corbett JJ, Feldon SE, Friedman DI, et al: Effect of acetazolamide on visual function in patients with idiopathic intracranial hypertension and mild visual loss: the idiopathic intracranial hypertension treatment trial. JAMA 311:1641-1651, 2014

38. Warder DE: Tethered cord syndrome and occult spinal dysraphism. Neurosurg Focus 10(1):e1, 2001

39. Wehby MC, O'Hollaren PS, Abtin K, Hume JL, Richards BJ: Occult tight filum terminale syndrome: results of surgical untethering. Pediatr Neurosurg 40:51-58, 2004

40. Williams LE, Vannemreddy PS, Watson KS, Slavin KV: The need in dural graft suturing in Chiari I malformation decompression: a prospective, single-blind, randomized trial comparing sutured and sutureless duraplasty materials. Surg Neurol Int 4:26, 2013

41. Xie YJ, Shargorodsky J, Lane AP, Ishii M, Solomon D, Moghekar A, et al: Perioperative continuous cerebrospinal fluid pressure monitoring in patients with spontaneous cerebrospinal fluid leaks. Int Forum Allergy Rhinol 5:71-77, 2015
42. Youmans JR, Winn HR: Youmans Neurological Surgery. Philadelphia: Saunders Elsevier, 2011

43. Zide BM, Wisoff JH, Epstein FJ: Closure of extensive and complicated laminectomy wounds. Operative technique. J Neurosurg 67:59-64, 1987

\section{Disclosures}

The authors report no conflict of interest concerning the materials or methods used in this study or the findings specified in this paper.

\section{Author Contributions}

Conception and design: Nejat, Shahjouei. Acquisition of data: Shahjouei, Hanaei, Habibi. Analysis and interpretation of data: all authors. Drafting the article: Shahjouei, Hanaei. Critically revising the article: Nejat, Habibi, Ansari. Reviewed submitted version of manuscript: all authors. Approved the final version of the manuscript on behalf of all authors: Nejat. Statistical analysis: Habibi, Hoseini. Administrative/technical/material support: Nejat, Habibi. Study supervision: Nejat.

\section{Correspondence}

Farideh Nejat, Department of Neurosurgery, Children's Hospital Medical Center, Tehran University of Medical Sciences, Mailbox: Tehran, F. Nejat, 14155-7854, Tehran, Iran. email: nejat@sina. tums.ac.ir. 